\title{
WASTEWATER TREATMENT IN DESICCATED COCONUT INDUSTRY
}

\author{
HYA Nerdana and DRIB Werellagama \\ Department of Civil Engineering, Faculty of Engineering, \\ Univers ty of Peradeniya, Peradeniya
}

Coconut products are the second argest agricultural export product in Sri-Lanka after tea. Desiccated Coconut (DC) accounts for almost $40 \%$ of the total export revenues from coconut products. Sri Lanka is the second largest producer of desiccated coconut in the world (after the Philippines) and the production is still growing rapidly. Sri Lanka is estimated to produce 50,000 tonnes of desiccated coconut per year accounting for $40 \%$ of the world production.

Most of coconut plantations and its related industries are located in the triangle of the three cities of Colombo, Kurunegala and Puttalam. Presently there are 64 DC mills in operation, of which around 50 are large-scale factories, processing over 100,000 coconuts per day. The remaining mills are medium scale; processing around 50,000 coconuts per day.

Some of the existing DC industries significantly contribute to the deterioration of the quality of the environment. According to thle 1993 report of Central Environmental Authority (CEA), desiccated coconut industry is the third major water polluter in Sri Lanka after natural rubber industry and concentrated latex industry.

One coconut gives approximately 0.151 of coconut water. Combined with wash water and sterilizing water, a factory processing 50,000 nuts/day discharges about $50 \mathrm{~m}^{3}$ of wastewater per day. A characteristic waste water cocktail from a DC mill comprises COD $8000 \mathrm{mg} / 1$, BOD $4000 \mathrm{mg} / \mathrm{L}$, SS $300 \mathrm{mg} / \mathrm{l}$, Nitrogen (nitrate, nitrite and ammonia) $50 \mathrm{mg} / 1$ and Phosphorous $10 \mathrm{mg} / 1$.The $\mathrm{pH}$ value is around 5.0.Most factories discharge their untreated or poorly treated effluent to general watercourses, er eating significant pollution and problems for downstream users.

In some DC mills some treatment is attempted, using physical treatment methods like screening and oil separation. Since the strength of the waste stream is very high, physical treatment alone is not enough. Chemical treatmen methods will cerate large amounts of sludge, which also has to be treated. Therefore the possibility of biological treatment was investigated and an aerobic bacteria mix named EM (effective nicroorganisms) was selected.

The treatment process sequence identified in this study is screening, oil separation, aeration, sedimentation, secondary aeration, secondary sedimentation and filtration. EM is added to both aeration tanks. The optimum volumes of EM to be added to the tanks are currently under investigation. Batch testing with EM shows $75 \%$ COD reduction by one aerator. With two aerators in tandem, it can reduce the COD values to comply with the Sri Lankan Standard for Discharge of Industrial Effluents in to Inland Surface Waters (1990). The treatment process developed in this research overcomes the odour problem. To ensure the effluent will not have free EM, it is chlorinated before discharge into the polishing filter for the final treatment step. 